\title{
Estimates of land and sea moisture contributions to the monsoonal rain over Kolkata, deduced based on isotopic analysis of rainwater
}

\author{
Shaakir Shabir Dar and Prosenjit Ghosh \\ Centre for Earth Sciences, Indian Institute of Science, Bangalore, 560012, India \\ Correspondence to: Prosenjit Ghosh (pghosh@ceas.iisc.ernet.in) \\ Received: 5 December 2016 - Discussion started: 14 December 2016 \\ Accepted: 8 March 2017 - Published: 27 April 2017
}

\begin{abstract}
Moisture sources responsible for rains over Kolkata during the summer monsoon can be traced using backward air-mass trajectory analysis. A summary of such trajectories between June and September suggest that these moisture parcels originate from the Arabian Sea and travel over the dry continental region and over the Bay of Bengal $(\mathrm{BoB})$ prior to their arrival at Kolkata. We use monthly satellite and ground-based observations of the hydrometeorological variables together with isotopic data of rainwater from Bangalore and Kakinada to quantify the contributions of advected continental and oceanic water vapour in the Kolkata rains. The vapour mass is modified during its transit from its original isotopic value due to addition of evaporated moisture from the $\mathrm{BoB}$, and further modification occurs due to the process of rainout during transport. The evaporated component is estimated using the Craig-Gordon equation. The rainout process is simulated using a Rayleigh fractionation model. In this simulation we assume that the initial isotopic composition of vapour originating from the continent is similar to the rainwater composition measured at Bangalore. In order to explain the monthly isotopic composition in southwest monsoon rainwater at Kolkata, we invoke $65-75 \%$ moisture contribution from the $\mathrm{BoB}$; the remaining moisture is from the continental land mass.
\end{abstract}

\section{Introduction}

Indian land mass receives rainfall during the summer due to winds favouring moisture transport from the region of the Intertropical Converge Zone (ITCZ) located over the Indian Ocean. The process of moisture transport from the oceanic region commences in June and continues until September. This period is generally termed as the Indian Summer Monsoon (ISM) or the Southwest Monsoon (SWM). Summer monsoon rain constitutes $50-90 \%$ of the total annual rainfall received by the entire country (Gadgil, 2003). The air parcel during its northward journey picks up vapour from the surrounding seas; namely the Arabian Sea and the Bay of Bengal (BoB). Studies have shown that the composition of surface seawater surrounding the Indian land mass can be isotopically distinguishable, i.e. heavier values for water in the Arabian Sea located in the west and dominated by strong evaporative forcing, whereas the $\mathrm{BoB}$ water in the east is characterized by lighter value due to the influence of rainfall and river runoff (Gupta and Deshpande, 2003; Rangarajan et al., 2013; Rahul et al., 2016a). Isotopic composition measured in the shallow groundwater along the transect between Kolkata and New Delhi were used in a simple box model to estimate the percentage of moisture contribution in rain due to the process of evapotranspiration (ET) (Krishnamurthy and Bhattacharya, 1991). In this study shallow groundwater over the Indo-Gangetic Plain was treated as the equivalent of rainwater due to its short residence time and the estimated presence of $\sim 40 \%$ moisture due to recycling of shallow groundwater or rainwater. This was further verified in a recent study where the average monthly (JuneSeptember) isotopic composition of rainwater measured at Kolkata and New Delhi was explained by supplementing $\sim 20 \%$ moisture from the Arabian Sea to a parcel, modified due to Rayleigh-based fractionation of the original moisture parcel originating from the $\mathrm{BoB}$, in addition to $\sim 45 \%$ mois- 
ture being included as the ET component from recycling. In a more recent observation on vapour isotopic composition from the northern flood plain station located at the city of Roorkee, three moisture sources for vapour were detected, namely BoB, western disturbances, and lake water from the nearby regions (Krishan et al., 2014). Satellite-based observations and pan evaporation data indicate that the quantity of moisture returned to the atmosphere by the process of evaporation is substantial and plays a significant role in governing the regional water budget. According to global estimates, the hydrological cycle involves an annual rate of evaporation of about $500000 \mathrm{~km}^{3}$ of water, around $86 \%$ of which come from the oceans, with the remainder originating from the continents (Quante and Matthias, 2006). Using the Eulerian moisture tracking method in a global study, Van der Ent et al. (2010) showed that about $40 \%$ of terrestrial precipitation originates from land evaporation. However, significant variations from this average global value can occur depending on position of station on the continent and net radiation influx, along with influence of factors like land use and land cover (Gimeno et al., 2012).

A quantitative understanding of the hydrological components involving advected and land-recycled moisture is possible using stable isotope tracers (Kendall and McDonnell, 2012). Stable isotopes of oxygen and hydrogen in water provide a method to determine contributions of land- and oceanderived moisture due to their distinct isotopic ratios. Isotopic ratios in rainwater and water vapour mirror the isotopic composition of moisture sources modified by the fractionation associated with the mechanism of precipitation during its transport to a continental site (Dansgaard, 1964; Rozanski et al., 1993; Gat, 2000; Araguás-Araguás et al., 2000; Gat, 2005; Yoshimura, 2015). Attempts have been made for the quantitative determination of the precipitation components using regional analytical models (e.g. Gat and Matsui, 1991; Krishnamurthy and Bhattacharya, 1991; Sengupta and Sarkar, 2006; Froehlich et al., 2008; Peng et al., 2011; Rahul et al., 2016a) and global physical models (e.g. Yoshimura et al., 2003, 2008, 2010; Jasechko et al., 2013; Keys et al., 2014) at different timescales.

The Global Network of Isotopes in Precipitation (GNIP) (International Atomic Energy Agency; IAEA) study over India offers several years of rainwater isotopic values at monthly resolution for different stations along the travel path. This database proves to be extremely useful to delineate the contribution of different moisture sources to the regional precipitation.

In this study we use the rainwater isotopic data from the BoB and three stations, namely Bangalore, Kakinada, and Kolkata. We have used simultaneous satellite-based meteorological observations in a two-component mixing model to deduce the moisture contribution from continental land mass due to advection (also designated as land-based moisture) and supply from evaporation of the BoB surface water during the year 2004.

\section{Data and methods}

The easterly winds during the SWM transport moisture that generates over the Arabian Sea to continental destinations over southern India (Rao, 1976). The global Lagrangian particle dispersion model, which runs using ECMWF (European Centre for Medium-Range Weather Forecasts) operational analysis for June, July, and August, reveals that the Arabian Sea and the northern Indian Ocean act as sources of $95 \%$ of the moisture responsible for precipitation over the Indian land mass (Gimeno et al., 2010, 2011). The isotopic composition of rainwater at Bangalore during the SWM of 2010 was explained using $70 \%$ moisture contribution from the Arabian Sea, while continental rainwater recycling contributed the rest (Rahul et al., 2016a). The moisture parcels originating from the Arabian Sea move over land under the prevailing easterly winds and are modified in terms of composition due to participation of moisture from land recycling. The measured isotopic composition of rain and/or vapour at Bangalore, situated equidistant $\sim 300 \mathrm{~km}$ inland from the Arabian Sea in the west and the BoB in the east, serves as an ideal representation of the isotopic signature of continental moisture. Backward air-mass trajectories indicate that the moisture parcel may travel further over land or over the BoB before re-entering the Indo-Gangetic Plain (Fig. 3). The SWM monsoon enters the Indo-Gangetic Plain through a corridor over the eastern coast near Kolkata.

The air masses were traced for $-48,-72$, and $-96 \mathrm{~h}$ at 200, 500, 1000, 1500, 2000, and $2500 \mathrm{~m}$ elevations above the mean sea level at Bangalore and Kolkata for all rainy days during the SWM of the year 2004 using the meteorological input from Reanalysis 2 data. It was determined that 2004 was a normal monsoon year. Indian Meteorological Department (IMD) defines a year as a normal monsoon year if the rainfall is anywhere from half to less than 1.5 times the normal rainfall (over the land area). Hybrid Single-Particle Lagrangian Integrated Trajectory (HYSPLIT) (Draxler and Hess, 1998) analysis from the NOAA Air Research Laboratory (http://www.arl.noaa.gov/ready/hysplit4.html) is used to track the air parcel back in time. HYSPLIT is a complete system used for computing simple air parcel trajectories as well as complex transport, dispersion, chemical transformation, and deposition simulations (Stein et al., 2015). The back trajectories for Bangalore and Kolkata are displayed in Fig. 3. The contribution of continental and BoB moisture to the rain precipitated at Kolkata during the SWM is modelled using the isotopic composition of rainwater collected at Bangalore and over the BoB. As the air parcel travels towards Kolkata, its isotopic composition is modified due to an interplay of processes like rainout and moisture addition from the BoB. To model the isotopic composition, the transect between Bangalore and Kolkata is divided into seven boxes of equal dimensions (Fig. 1). It was designed in such a way that the majority of air-mass trajectories pass through it. This size of the boxes is chosen so that the total precipitable water 
for each box remains fairly uniform. The monthly averaged (June, July, August, and September) isotopic $\delta^{18} \mathrm{O}$ values for the SWM of different years $(2004,2008,2010$, and 2013) were extracted from IAEA data and other publications. The monthly averaged $\delta^{18} \mathrm{O}$ value at Kolkata (2004) is modelled by adopting the isotopic composition of monthly rainwater at Bangalore as an original value (initial condition). While simulating the model with two-component mixing, we assumed near-identical (similar to Bangalore) values for moisture originating from the continent. The $\delta^{18} \mathrm{O}$ values measured in the rainwater at Kakinada (2004), which is located within the modelling transect, are useful for validating our assumption.

Together with rainwater isotopic data, monthly averaged meteorological data (2004) and isotopic composition of the BoB surface water have been used in this study. Precipitation data from the Tropical Rainfall Measuring Mission (TRMM) project (Huffman et al., 2010) (3B42 V7 derived); Goddard Space Flight Center, Distributed Active Archive Center (GSFC DAAC) (http://trmm.gsfc.nasa.gov/); and the Total Precipitable Water, Air Temperature, Relative Humidity, and Wind Speed datasets from the Reanalysis 2 (Kanamitsu et al., 2002) (http://www.esrl.noaa. gov/psd/data/gridded/data.ncep.reanalysis $2 . h t m l$ ) have been used. Surface-water isotopic composition over the BoB was extracted from the Global Seawater Oxygen-18 Database (V-1.21) (Schmidt et al., 1999) (http://data.giss.nasa.gov/ o18data/). The monthly averaged oxygen isotopic composition $\left(\delta^{18} \mathrm{O}\right)$ for the SWM of the year 2004 was retrieved from the IAEA-GNIP (http://www-naweb.iaea.org/napc/ih/ IHS_resources_gnip.html) dataset for the stations located at Bangalore, Kolkata, and Kakinada. The isotopic composition of rainwater at Bangalore for the year 2008 was obtained from Rangarajan et al. (2013), while for other years (2010 and 2013), it was obtained from Rahul et al. (2016a, b). Figure 2 depicts the oxygen isotopic composition $\left(\delta^{18} \mathrm{O}\right)$ for Bangalore, Kakinada, and Kolkata. Table 1 shows the oxygen isotopic composition $\left(\delta^{18} \mathrm{O}\right)$ of $\mathrm{BoB}$ rainfall for the year 2012 collected during the CTCZ-2012 expedition. An average isotopic composition of rainfall recorded over the $\mathrm{BoB}$ is used to obtain a representative isotopic value for demonstrating the evaporated moisture over the $\mathrm{BoB}$ using the CraigGordon equation.

\subsection{Designing Rayleigh's model for rainout}

Rayleigh's distillation equation is modified to include a vapour mixing process. The isotopic composition of the continental and the $\mathrm{BoB}$ vapour mixture has been numerically simulated using the improvised version of the Rayleigh distillation model. Figure 4 shows a schematic representation of the numerical expression and procedure. The model is run for the months covering the SWM period. The oxygen isotopic composition of rainwater at the continental stations and the $\mathrm{BoB}$, meteorological parameters, $\mathrm{BoB}$ surface-water iso-

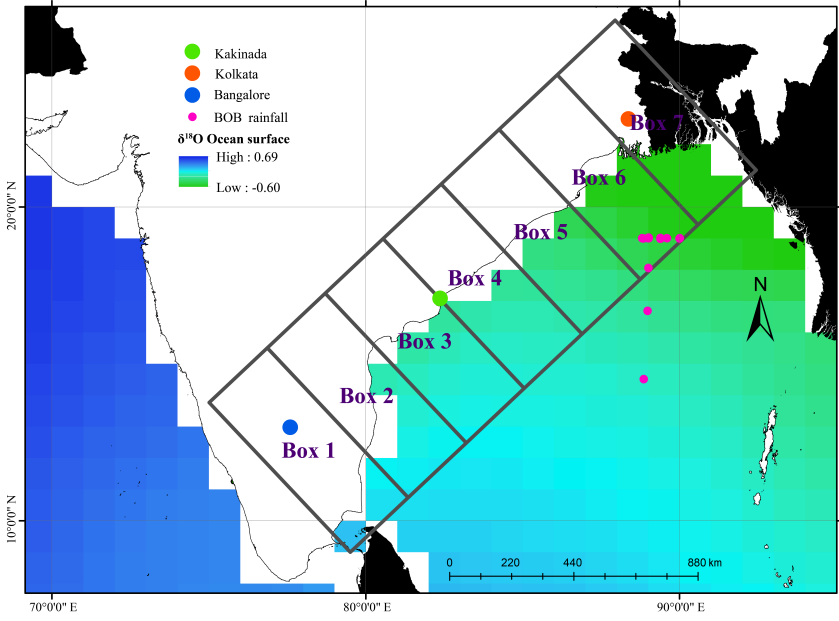

Figure 1. Study area and modelling transect divided into boxes of equal dimensions. The modelling transect was chosen such that the majority of the HYSPLIT trajectories pass through it. Orange, green, and blue circles represent the locations of the Kolkata, Kakinada, and Bangalore stations respectively. The ocean layer represents the $\delta^{18} \mathrm{O}$ surface-water isotopic composition (Schmidt et al., 1999). The isotopic composition remains fairly constant over the BoB, with slightly depleted values near the Ganges Delta (Box 7) due to freshwater mixing. Solid pink circles represent the locations of rainfall collected for isotopic measurements over the BoB.

topic composition, and satellite-based precipitation data are used as input parameters to actuate the model. The $\delta^{18} \mathrm{O}$ of Kolkata rain is predicted after introducing modification in the isotopic composition of residual vapour measured at Bangalore. The procedure involves accounting for the rainout in the Rayleigh's distillation model and a two-component mixing formulation where advected vapour and the vapour supplied from the $\mathrm{BoB}$ are mixed to generate an integrated vapour.

$\delta^{18} \mathrm{O}$ value in vapour over the Bangalore region is used as an original isotopic value (initial condition) to start the model run. Isotopic composition of the vapour is calculated from the measured isotopic values of rainwater, assuming an equilibrium fractionation. As the moisture parcel loses water by the process of rainout, the residual vapour isotopic composition is given by

$\delta V_{i}=\left(\delta V_{i_{0}}+1\right) \times f_{i}^{\alpha_{i}-1}-1$,

where $\delta V_{i}$ is the isotopic composition of vapour after rainout in the $i$ th box, $\delta V_{i_{0}}$ is the initial isotopic composition of vapour, $\alpha_{i}$ is the fractionation factor (Majoube, 1971) calculated for the dew point temperature at $850 \mathrm{mb}$ pressure level for the $i$ th box, and $f_{i}$ is the fraction of vapour remaining in the air-mass, given by

$f_{i}=\frac{W_{1}-\sum P_{i}}{W_{i}}$,

where $W$ is the total precipitable water over the box and $P$ is rainfall over each box. The subscript denotes the box number. 
Table 1. Rainwater isotopic composition and collection locations over the BoB collected during 2012 expedition.

\begin{tabular}{|c|c|c|c|}
\hline S no. & $\begin{array}{l}\text { Latitude } \\
\text { (decimal } \\
\text { degrees) }\end{array}$ & $\begin{array}{r}\text { Longitude } \\
\text { (decimal } \\
\text { degrees) }\end{array}$ & $\delta^{18} \mathrm{O}(\% \circ)$ \\
\hline 1 & 18.99 & 89.39 & -1.74 \\
\hline 2 & 18.99 & 89.39 & -1.55 \\
\hline 3 & 18.99 & 89.39 & -1.53 \\
\hline 4 & 19.02 & 89.39 & -1.31 \\
\hline 5 & 19.00 & 89.60 & -4.26 \\
\hline 7 & 19.00 & 90.00 & -4.80 \\
\hline 8 & 19.00 & 88.84 & -3.71 \\
\hline 9 & 19.00 & 88.84 & -3.58 \\
\hline 10 & 19.00 & 88.84 & -3.55 \\
\hline 11 & 19.01 & 88.80 & -2.60 \\
\hline 12 & 19.01 & 89.00 & -3.18 \\
\hline 13 & 19.01 & 89.00 & -0.06 \\
\hline 14 & 19.01 & 89.01 & -2.04 \\
\hline 15 & 19.01 & 89.01 & -2.14 \\
\hline 17 & 19.01 & 89.01 & -1.42 \\
\hline 18 & 19.00 & 89.01 & -1.54 \\
\hline 19 & 19.02 & 89.01 & -1.32 \\
\hline 20 & 19.02 & 89.01 & -0.06 \\
\hline 21 & 19.02 & 89.02 & -0.04 \\
\hline 22 & 19.02 & 89.02 & -3.55 \\
\hline 23 & 19.00 & 89.02 & -2.98 \\
\hline 24 & 19.00 & 89.00 & -2.68 \\
\hline 25 & 19.01 & 89.00 & -2.84 \\
\hline 26 & 19.01 & 89.01 & -0.71 \\
\hline 27 & 19.01 & 89.01 & -0.78 \\
\hline 28 & 19.01 & 89.00 & -0.88 \\
\hline 29 & 19.01 & 89.00 & -0.97 \\
\hline 30 & 19.01 & 89.01 & -0.81 \\
\hline 31 & 19.01 & 89.01 & -0.14 \\
\hline 32 & 18.06 & 89.01 & -0.57 \\
\hline 33 & 16.69 & 88.98 & -1.98 \\
\hline 34 & 14.51 & 88.86 & -0.36 \\
\hline
\end{tabular}

Upon leaving the continental land mass, the air parcels traverse the $\mathrm{BoB}$ and pick up moisture along the way, leading to a modification of the original vapour isotopic value. In order to account for this change, the modified equation to calculate the fraction of vapour remaining in the $i$ th box is

$f_{i}=\frac{W_{1}-\left(P_{i}-E_{i-1}\right)}{W_{i}}$.

$\mathrm{E}$ is the evaporation contribution from the BoB. Moisture in the air mass is replenished as it travels over the BoB. The isotopic composition of the evaporation flux over each box is estimated using the Craig and Gordon (1965) model:

$\delta V_{\mathrm{iBoB}}=\frac{\delta_{l}-h \delta_{a}-\epsilon^{*}-\epsilon}{1-h}$,

where $\delta V_{\mathrm{iBoB}}$ is the isotopic composition of the evaporation flux supplied by the $\mathrm{BoB} ; \delta_{l}$ is the $\mathrm{BoB}$ surface-water iso-

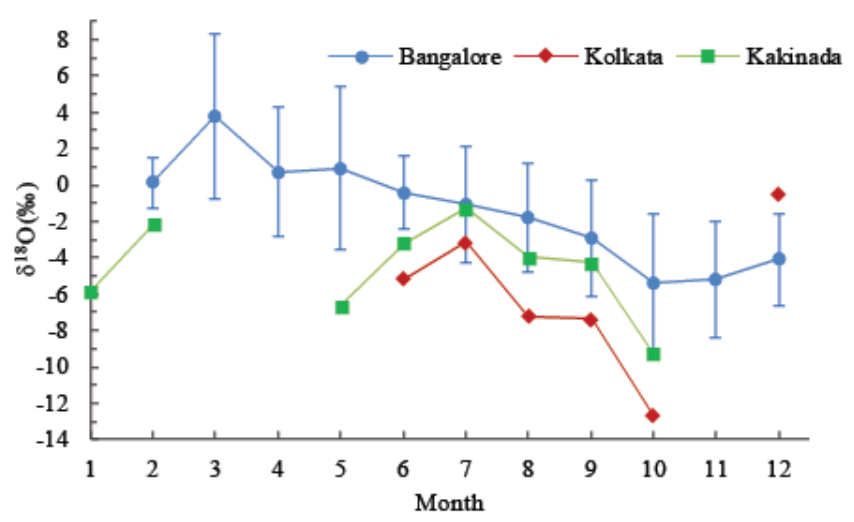

Figure 2. Monthly averaged $\delta^{18} \mathrm{O}$ isotopic composition for the Bangalore (blue circle) station. The bars represent the standard deviation from monthly mean. Isotopic composition of Kakinada (green square) and Kolkata (red diamond) for the year 2004.

topic composition; $h$ is the relative humidity as a fraction of unity; $\delta_{a}$ is the isotopic composition of the vapour over the $\mathrm{BoB}$, calculated assuming equilibrium relationship between rain and vapour over the $\mathrm{BoB} ; \epsilon^{*}$ is the equilibrium enrichment factor; and $\epsilon$ is the kinetic enrichment factor given by Merlivat and Jouzel (1979), where $\epsilon^{*}=(\alpha-1) \alpha-10^{3}$ and $\alpha$ is the equilibrium fractionation factor.

The isotopic composition of the resultant vapour formed by mixing two moisture sources depletes the heavy isotopes with progressive rainout. The depleted vapour moves to the next box and is mixed with the moisture generated by the $\mathrm{BoB}$. The resulting vapour undergoes rainout and so on, until the final value in the Kolkata rainwater is achieved.

\section{Discussion and results}

After spawning from the Arabian Sea, as the air mass enters the Indian land mass through its western coast, the constitution of the moisture parcel is modified due to the process of rainout and addition of continental vapour or BoB vapour before re-entering the corridor of the Indo-Gangetic Plain through the east coast. The isotopic composition of vapour over Bangalore is taken as the representative of the continental vapour. The isotopic composition of the air mass is modified as it moves towards Kolkata under the prevailing wind direction during the SWM. The rainwater $\delta^{18} \mathrm{O}$ value decreases consistently as the SWM period progresses and follows patterns similar to each other for the sites at Kolkata and Bangalore. The $\delta^{18} \mathrm{O}$ rainfall approaches a minimum for the month of October for both locations (Fig. 2). A consistent pattern recorded in the isotopic values during the SWM period at both the sites suggests a common source for moisture responsible for rain. This was confirmed from the observation documenting the backward trajectories for both the stations. However, there were situations during the SWM period where a large difference in the monthly rainwater iso- 


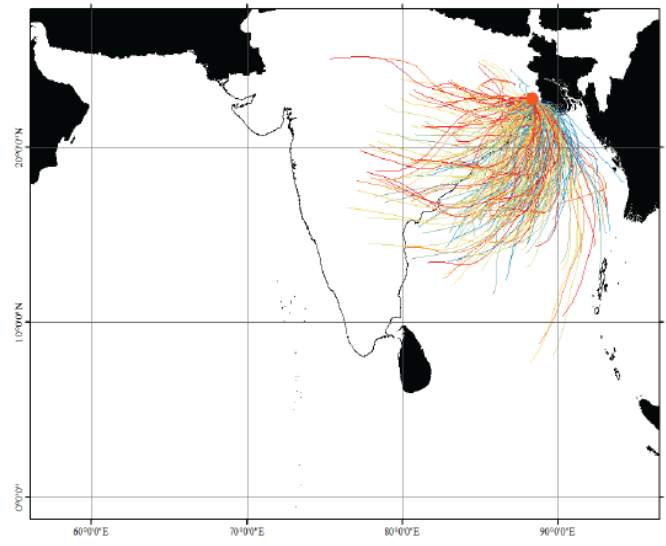

(a) Kolkata $-48 \mathrm{~h}$

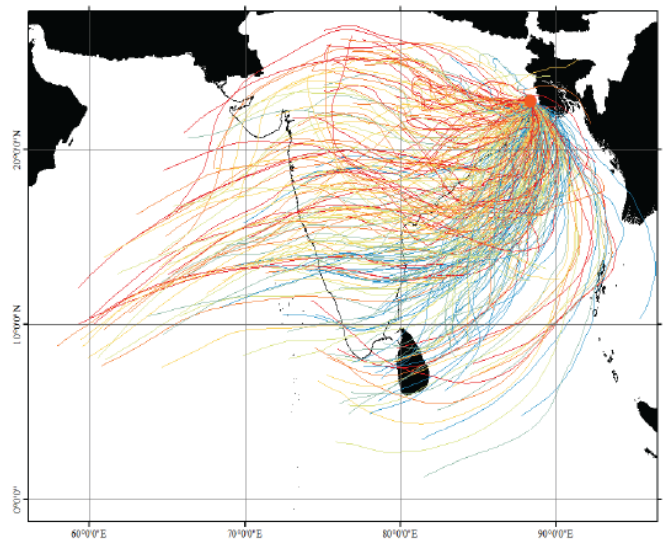

(c) Kolkata $-96 \mathrm{~h}$

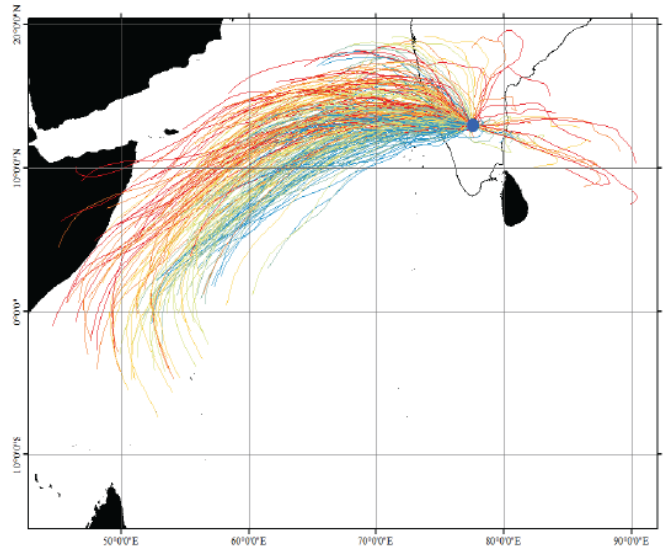

(e) Bangalore $-72 \mathrm{~h}$

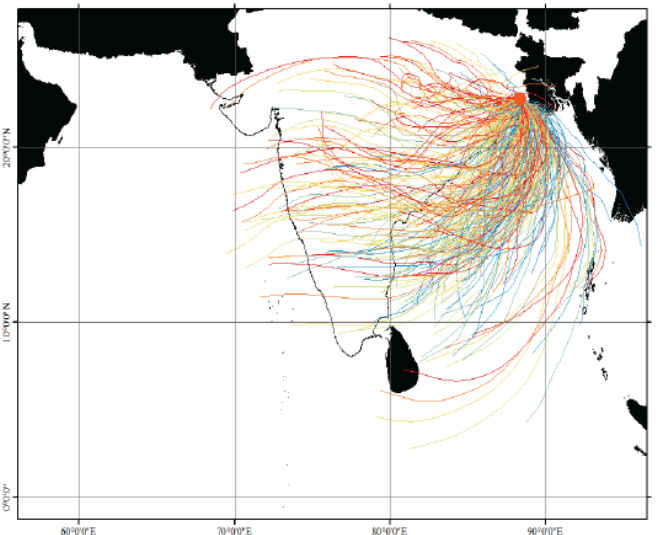

(b) Kolkata $-72 \mathrm{~h}$

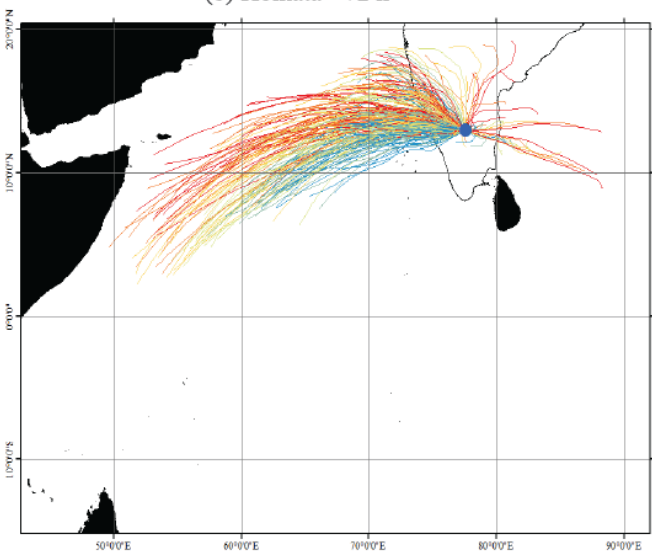

(d) Bangalore $-48 \mathrm{~h}$

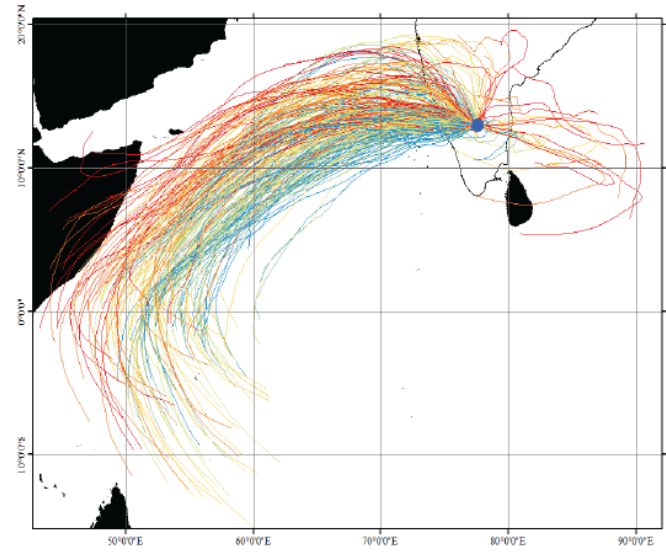

(f) Bangalore $-96 \mathrm{~h}$

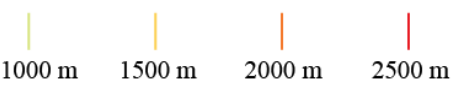

\section{Trajectory height above mean sea level}

Figure 3. Backward air-mass trajectories $(-48,-72$, and $-96 \mathrm{~h})$ prior to a rainy day at 200, 500, 1000, 1500, 2000, and $2500 \mathrm{~m}$ above mean sea level for a single year (2004) at Bangalore and Kolkata during all rainy days of the SWM. The modelling transect is chosen such that the majority of the trajectories pass through it.

topic data of the two stations was noted. Conversely, such a lack of consistent temporal patterns suggests involvement of different sources. In the time series analysis of rainfall $\delta^{18} \mathrm{O}$, a monthly lag in registering the isotopic minima was noticeable, corresponding to the timing of rainfall maxima at both the stations. This indirectly implies participation of a 


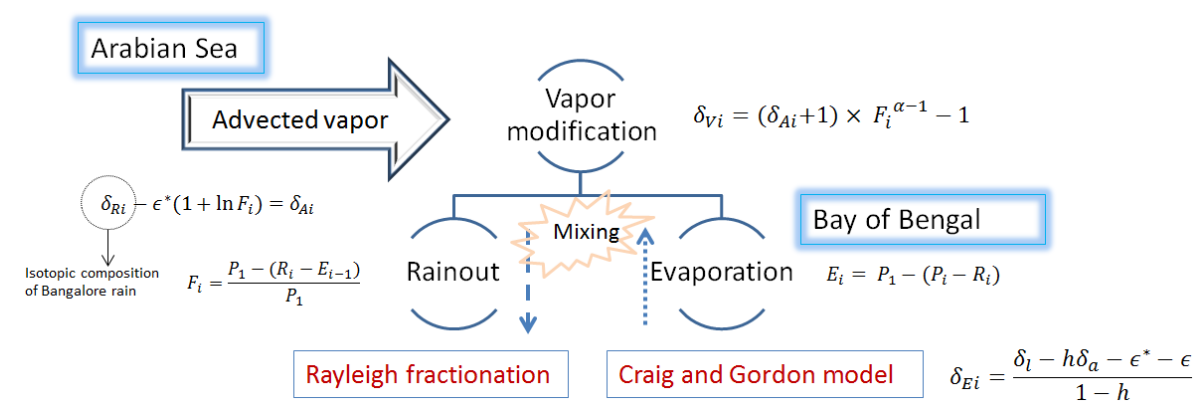

Figure 4. Schematic of the modelling procedure involved.

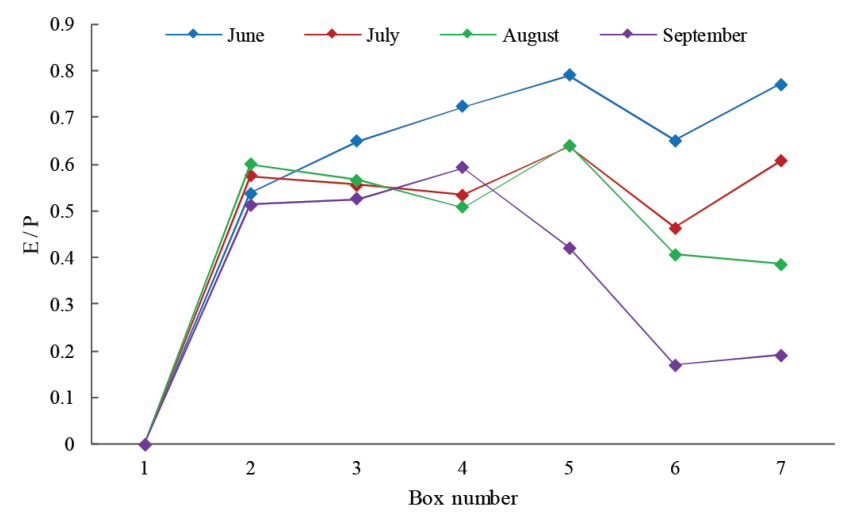

Figure 5. E / P ratio for each box of the modelling transect for the SWM months of 2004.

second moisture source in the case of Kolkata precipitation. Such a pattern can be consistently explained employing the Rayleigh distillation model after taking into account the rainout process and mixing of vapour generated from the BoB region.

The air parcel during the SWM period moves towards Kolkata from Bangalore under the prevailing wind, where the original isotopic composition is modified due to the interplay of (i) rainout, which follows Rayleigh-type distillation and ii) mixing of the vapour generated over the BoB. For $E=0$, i.e. assuming no moisture contribution from the $\mathrm{BoB}$, for the whole season the modelled derived $\delta^{18} \mathrm{O}$ value for rainfall at Kolkata is $-8.04 \pm 0.96 \%$. This value is lower than the observed value by $2.3 \%$.

Table 2 shows fraction of vapour remaining in the air mass $(f)$ and the isotopic composition of vapour $\left(\delta^{18} \mathrm{O}_{\mathrm{v}}\right)$ calculated over each modelling box for the SWM months. The vapour isotopic composition decreases as the monsoon progresses, with most depleted values observed during the month of September. This depletion is indicative of the gradual reduction in contribution of $\mathrm{BoB}$ moisture due to the saturated nature of incoming air parcels laden with vapour originating from the Arabian Sea region. Figure 5 shows the $\mathrm{E} / \mathrm{P}$ ratio for each of the boxes ( $E=0$ for the first box since the BoB contribution at Bangalore is assumed to be zero).
The mixing of the advected component and the BoB component leads to modification of the vapour isotopic composition. The final isotopic composition of the vapour is governed by the relative contributions of both these sources. Sengupta and Sarkar (2006) held the cyclonic disturbances originating from the BoB responsible for the maximum drop in isotopic values during the early phase of the SWM. There is a tendency of low-pressure zones to develop and remain confined to $\sim 20^{\circ} \mathrm{N}$ in the $\mathrm{BoB}$ during onset time. The position of such low-pressure zones shifts southward to $\sim 15^{\circ} \mathrm{N}$ during the later phase of the SWM. This explains the isotopic variability recorded in Kolkata rainfall (Sengupta and Sarkar, 2006) during the SWM period. It is worth mentioning that the significant differences in the evaporation contribution arise from box numbers 5, 6, and 7 . The evaporation contribution from the first four boxes remains somewhat the same for the whole period of the SWM. For the month of September, the contribution from boxes 5, 6, and 7 is smaller than boxes $1-4$. This can be attributed to the decreasing strength of the monsoonal wind and more contribution of moisture originating from the continent. The Rayleigh's distillation model is used to track further changes in the isotopic composition of the vapour $\left(\delta^{18} \mathrm{O}\right)$, as the vapour progressively loses water during condensation. Figure 6 depicts the model results at monthly and the seasonal timescales. The isotopic composition of vapour is calculated from the rainfall isotopic composition calculated assuming equilibrium between vapour and the liquid phase. The model run used three values as initial conditions $\left(\delta^{18} \mathrm{O}\left(\delta^{18} \mathrm{O}_{\text {mean }}+\mathrm{SD}\right), \delta^{18} \mathrm{O}_{\text {mean }}\right.$, and $\left(\delta^{18} \mathrm{O}_{\text {mean }}-\mathrm{SD}\right)$, capturing the uncertainty or spread in the continental vapour isotopic value measured at Bangalore. This includes monthly uncertainty in rainwater values based on number of samples collected during a month. The model performance is fair, within the uncertainty limits at a monthly timescale. However, the model performance improved significantly when the same simulation was run with average $\delta^{18} \mathrm{O}$ for the entire SWM period. The modelled value is $-6.05( \pm 0.69) \%$ and the actual observed value is $5.76( \pm 1.99) \%$. 
Table 2. Fraction of vapour remaining over each box and the modelled isotopic composition of vapour over each box for the year 2004. The values in brackets are the standard deviation from the calculated mean values.

\begin{tabular}{lrrrrrrrl}
\hline Box & 1 & 2 & 3 & 4 & 5 & 6 & 7 & Month \\
\hline$f$ & 0.9354 & 0.9676 & 0.8748 & 0.9903 & 0.8588 & 0.8872 & 0.6804 & \\
$\delta^{18} \mathrm{O}_{\mathrm{v}}(\% \circ)$ & -13.11 & -13.1 & -13.08 & -13.08 & -13.06 & -13.03 & -12.98 & June \\
& $( \pm 2.57)$ & $( \pm 2.58)$ & $( \pm 2.50)$ & $( \pm 2.52)$ & $( \pm 2.39)$ & $( \pm 2.33)$ & $( \pm 1.96)$ & \\
\hline$f$ & 0.9262 & 0.9586 & 0.8895 & 0.9295 & 0.8369 & 0.7504 & 0.9125 & \\
$\delta^{18} \mathrm{O}_{\mathrm{v}}(\% \circ)$ & -13.24 & -13.23 & -13.22 & -13.2 & -13.18 & -13.16 & -13.12 & July \\
& $( \pm 2.75)$ & $( \pm 2.74)$ & $( \pm 2.75)$ & $( \pm 2.74)$ & $( \pm 2.73)$ & $( \pm 2.73)$ & $( \pm 2.72)$ & \\
\hline$f$ & 0.9135 & 0.9591 & 0.888 & 0.9407 & 0.8192 & 0.9286 & 0.8327 & \\
$\delta^{18} \mathrm{O}_{\mathrm{v}}(\% \circ)$ & -14.19 & -14.18 & -14.16 & -14.15 & -14.12 & -14.11 & -14.08 & August \\
& $( \pm 2.95)$ & $( \pm 2.96)$ & $( \pm 2.95)$ & $( \pm 2.94)$ & $( \pm 2.94)$ & $( \pm 2.93)$ & $( \pm 2.93)$ & \\
\hline$f$ & 0.8987 & 0.9511 & 0.8986 & 0.8859 & 0.9103 & 0.8673 & 0.7761 & \\
$\delta^{18} \mathrm{O}_{\mathrm{v}}(\% \circ)$ & -15.32 & -15.31 & -15.29 & -15.27 & -15.25 & -15.23 & -15.19 & September \\
& $( \pm 3.21)$ & $( \pm 3.21)$ & $( \pm 3.20)$ & $( \pm 3.20)$ & $( \pm 3.20)$ & $( \pm 3.19)$ & $( \pm 3.18)$ & \\
\hline
\end{tabular}
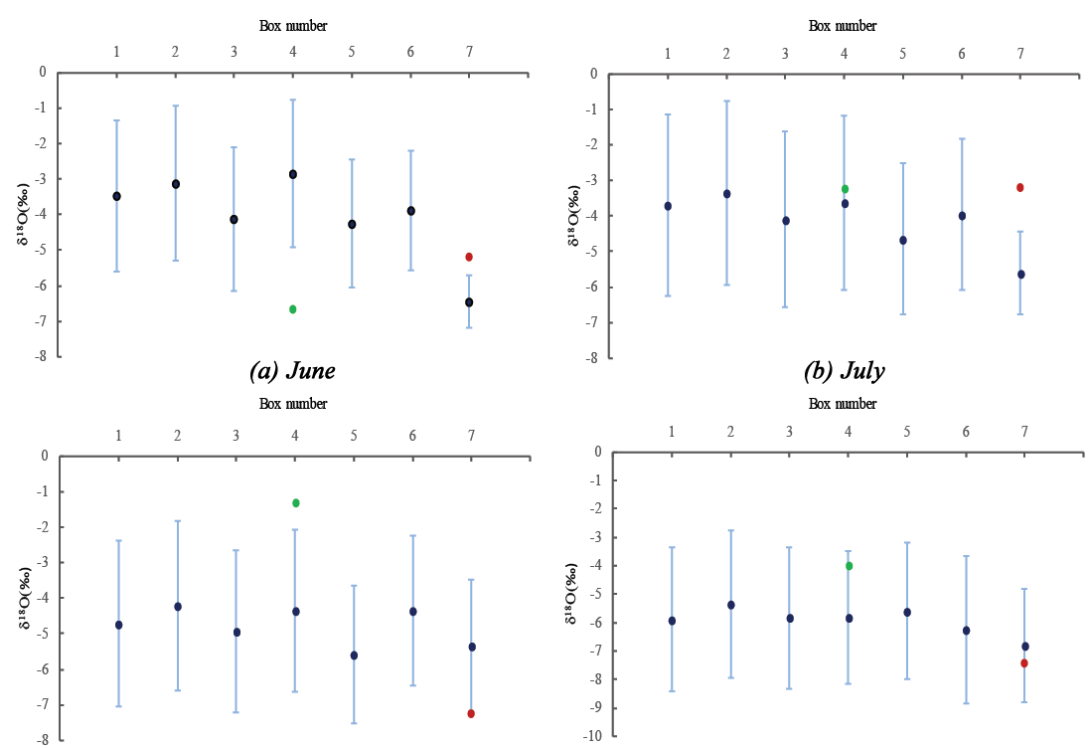

(c) August

(d) September

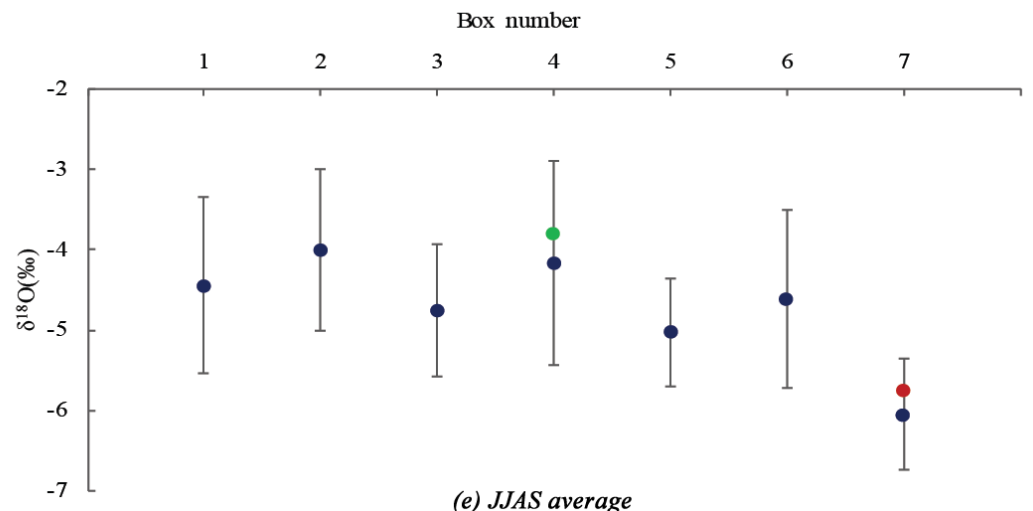

Figure 6. Dark blue represents the mean modelled $\delta^{18} \mathrm{O}(\%)$ isotopic composition of rain over each box as calculated from Rayleigh's distillation Eq. (5a-d) for the individual SWM months and e for the whole period of the SWM. The bars represent the standard deviation. Green and red solid circles represent the mean observed isotopic composition of rain at Kakinada and Kolkata respectively. 


\subsection{Model validation}

Figure 6 depicts the mean modelled isotopic value for rain at each box, with error bars representing the standard deviation from the mean isotopic value obtained from $\left(\delta^{18} \mathrm{O}\left(\delta^{18} \mathrm{O}_{\text {mean }}+\mathrm{SD}\right), \delta^{18} \mathrm{O}_{\text {mean }}\right.$, and $\left(\delta^{18} \mathrm{O}_{\text {mean }}-\mathrm{SD}\right)$ uncertainty in the initial vapour isotopic value. To validate our model prediction, the results are compared with the isotopic composition of rain at Kakinada, which lies in the transport pathway. The station lies in Box 4 of the transect (Fig. 1), and the $\delta^{18} \mathrm{O}$ of rain observed at Kakinada during the SWM is $-3.8( \pm 2.23) \%$ o. The observed value is very close to the model-predicted value of $-4.16( \pm 1.27) \%$. The model simulation yields a varying monthly contribution of vapour from land and oceanic sources. The $\mathrm{BoB}$ acts as an active source of moisture at the beginning of the SWM and its contribution to vapour as simulated by the model over Kolkata (Box 7) given as a percentage of the total precipitable water is $92 \pm 8 \%$ in June, $73 \pm 16 \%$ in July, $62 \pm 17 \%$ in August, and $47 \pm 17 \%$ in September. The BoB vapour supply diminishes as the monsoon gradually becomes weaker, and wind patterns reverse upon onset of north easterlies.

\section{Conclusions}

In this study we quantified the source of moisture precipitating as rain at Kolkata. The BoB is a major moisture contributor to precipitation at Kolkata, supplying overall $65-75 \%$ of the total precipitation during the entire SWM and the continental contribution varies from 25 to $35 \%$. The contribution of the $\mathrm{BoB}$ as the source of moisture at Kolkata attains a maximum at the commencement of the SWM during June but as strength of the monsoon decreases, the moisture contribution from $\mathrm{BoB}$ diminishes, while the role of continental vapour becomes important. The performance of the model is limited at a monthly timescale but performs well for the whole period of the SWM within the limit of uncertainty. The limitations at a monthly scale may arise due to the model assumption where the isotopic composition of the BoB surface water and the isotopic composition of rain over the BoB were held constant over the entire duration of the SWM. This assumption was made due to the unavailability of high-resolution datasets over the BoB. The performance of the model can be improved taking into consideration the monthly variation in the vapour and surface-water isotopic composition of rainfall over the BoB. This is the first estimate of such a kind where variable contribution of continental moisture in rain over Kolkata is invoked to explain the observation in the $\delta^{18} \mathrm{O}$ of rainwater measured at Kolkata. The findings have major implications for the regional water vapour budget in the context of past and future climatic scenarios. The role of phenomena like the El Niño Southern Oscillation or Indian Ocean Dipole on the relative contributions of continental and oceanic sources during the SWM can be investigated with simultaneous observation.
Data availability. All the data used in this study are available in online public data banks and published papers.

Competing interests. The authors declare that they have no conflict of interest.

Acknowledgements. We would like to thank the reviewers and SK Bhattacharya for their help in improving the quality of the paper and Surajit Mondal for the BoB rain isotope data.

Edited by: S. M. Vicente Serrano

Reviewed by: R. J. van der Ent and one anonymous referee

\section{References}

Araguás-Araguás, L., Froehlich, K., and Rozanski, K.: Deuterium and oxygen-18 isotope composition of precipitation and atmospheric moisture, Hydrol. Process., 14, 1341-1355, 2000.

Craig, H. and Gordon, L. I.: Deuterium and oxygen 18 variations in the ocean and the marine atmosphere, in: proc. Stable Isotopes in Oceanographic Studies and Paleotemperatures, Spoleto, Italy, edited by: Tongiogi, E., 9-130, V. Lishi e F., Pisa, 1965.

Dansgaard, W.: Stable isotopes in precipitation, Tellus, 16, 436468, 1964.

Draxler, R. R. and Hess, G.: An overview of the HYSPLIT_4 modelling system for trajectories, Aust. Meteorol. Mag., 47, 295308, 1998.

Froehlich, K., Kralik, M., Papesch, W., Rank, D., Scheifinger, H., and Stichler, W.: Deuterium excess in precipitation of Alpine regions-moisture recycling, Isot. Environ. Healt. S., 44, 61-70, 2008.

Gadgil, S.: The Indian monsoon and its variability, Annu. Rev. Earth Planet. Sc., 31, 429-467, 2003.

Gat, J.: Some classical concepts of isotope hydrology, in: Isotopes in the Water Cycle, Springer, Netherlands, 127-137, 2005.

Gat, J. and Matsui, E.: Atmospheric water balance in the Amazon Basin: an isotopic evapotranspiration model, J. Geophys. Res.Atmos., 96, 13179-13188, 1991.

Gat, J. R.: Atmospheric water balance the isotopic perspective, Hydrol. Process., 14, 1357-1369, 2000.

Gimeno, L., Drumond, A., Nieto, R., Trigo, R. M., and Stohl, A.: On the origin of continental precipitation, Geophys. Res. Lett., 37, L13804, doi:10.1029/2010GL043712, 2010.

Gimeno, L., Nieto, R., Drumond, A., Durán-Quesada, A. M., Stohl, A., Sodemann, H., and Trigo, R. M.: A close look at oceanic sources of continental precipitation, EOS Transactions American Geophysical Union, 92, 193-194, 2011.

Gimeno, L., Stohl, A., Trigo, R. M., Dominguez, F., Yoshimura, K., Yu, L., Drumond, A., Durán-Quesada, A. M., and Nieto, R.: Oceanic and terrestrial sources of continental precipitation, Rev. Geophys., 50, RG4003, doi:10.1029/2012RG000389, 2012.

Gupta, S. and Deshpande, R.: Synoptic hydrology of India from the data of isotopes in precipitation, Curr. Sci., 85, 1591-1595, 2003.

Huffman, G. J., Adler, R. F., Bolvin, D. T., and Nelkin, E. J.: The TRMM multi-satellite precipitation analysis (TMPA), in: Satel- 
lite rainfall applications for surface hydrology, Springer, Netherlands, 3-22, 2010

Jasechko, S., Sharp, Z. D., Gibson, J. J., Birks, S. J., Yi, Y., and Fawcett, P. J.: Terrestrial water fluxes dominated by transpiration, Nature, 496, 347-350, 2013.

Kanamitsu, M., Ebisuzaki, W., Woollen, J., Yang, S.-K., Hnilo, J., Fiorino, M., and Potter, G.: Ncep-doe amip-ii reanalysis (r-2), B. Am. Meteorol. Soc., 83, 1631-1643, 2002.

Kendall, C. and McDonnell, J. J.: Isotope tracers in catchment hydrology, Elsevier, 2012.

Keys, P. W., Barnes, E. A., van der Ent, R. J., and Gordon, L. J.: Variability of moisture recycling using a precipitationshed framework, Hydrol. Earth Syst. Sci., 18, 3937-3950, doi:10.5194/hess-18-3937-2014, 2014.

Krishan, G., Rao, M. S., Kumar, B., Kumar, C. P., Kumar, S., Jaiswal, R. K., Rao, Y. R. S., Tripathi, S., Kumar, M., Garg, P. K., and Kumar, P.: Monitoring of Southwest Monsoon using isotope analysis of ground level vapour (Glv) in Indian SubContinent, Journal of Earth Science and Climate Change, 5, doi:10.4172/2157-7617.1000224, 2014.

Krishnamurthy, R. and Bhattacharya, S.: Stable oxygen and hydrogen isotope ratios in shallow ground waters from India and a study of the role of evapotranspiration in the Indian monsoon, in: Stable Isotope Geochemistry: A Tribute to Samuel Epstein, vol. 3, Geochemical Society Special Publications, 187193, 1991

Majoube, M.: Fractionnement en oxygene-18 et en deuterium entre l'eau et sa vapeur, J. Chim. Phys, 68, 1423-1436, 1971.

Merlivat, L. and Jouzel, J.: Global climatic interpretation of the deuterium-oxygen 18 relationship for precipitation, J. Geophys. Res.-Oceans, 84, 5029-5033, 1979.

Peng, T.-R., Liu, K.-K., Wang, C.-H., and Chuang, K.-H.: A water isotope approach to assessing moisture recycling in the island-based precipitation of Taiwan: A case study in the western Pacific, Water Resour. Res., 47, W08507, doi:10.1029/2010WR009890, 2011.

Quante, M. and Matthias, V.: Water in the Earth's atmosphere, in: Journal de Physique IV (Proceedings), vol. 139, EDP sciences, 37-61, 2006.

Rahul, P., Ghosh, P., and Bhattacharya, S.: Rainouts over the Arabian Sea and Western Ghats during moisture advection and recycling explain the isotopic composition of Bangalore summer rains, J. Geophys. Res.-Atmos., 121, 6148-6163, 2016a.
Rahul, P., Ghosh, P., Bhattacharya, S., and Yoshimura, K.: Controlling factors of rainwater and water vapor isotopes at Bangalore, India: Constraints from observations in 2013 Indian monsoon, J. Geophys. Res.-Atmos., 121, 13936-13952, doi:10.1002/2016JD025352, 2016b.

Rangarajan, R., Ghosh, P., and Naggs, F.: Seasonal variability of rainfall recorded in growth bands of the Giant African Land Snail Lissachatina fulica (Bowdich) from India, Chem. Geol., 357, 223-230, 2013.

Rao, Y.: Southwest monsoon, vol. 1, India Meteorological Department, Meteorological Monograph, Synoptic Meteorology, 1976.

Rozanski, K., Araguás-Araguás, L., and Gonfiantini, R.: Isotopic patterns in modern global precipitation, Climate change in continental isotopic records, 1-36, doi:10.1029/GM078p0001, 1993.

Schmidt, G., Bigg, G., and Rohling, E.: Global seawater oxygen-18 database-v1. 21, http://data.giss.nasa.gov/o18data, 1999.

Sengupta, S. and Sarkar, A.: Stable isotope evidence of dual (Arabian Sea and Bay of Bengal) vapour sources in monsoonal precipitation over north India, Earth Planet. Sc. Lett., 250, 511-521, 2006.

Stein, A., Draxler, R., Rolph, G., Stunder, B., Cohen, M., and Ngan, F.: NOAA's HYSPLIT atmospheric transport and dispersion modeling system, B. Am. Meteorol. Soc., 96, 2059-2077, 2015.

Van der Ent, R. J., Savenije, H. H., Schaefli, B., and Steele-Dunne, S. C.: Origin and fate of atmospheric moisture over continents, Water Resour. Res., 46, W09525, doi:10.1029/2010WR009127, 2010.

Yoshimura, K.: Stable water isotopes in climatology, meteorology, and hydrology: A review, J. Meteorol. Soc. Jpn. Ser. II, 93, 513533, 2015.

Yoshimura, K., Oki, T., Ohte, N., and Kanae, S.: A quantitative analysis of short-term ${ }^{18} \mathrm{O}$ variability with a Rayleigh-type isotope circulation model, J. Geophys. Res.-Atmos., 108, 4647, doi:10.1029/2003JD003477, 2003

Yoshimura, K., Kanamitsu, M., Noone, D., and Oki, T.: Historical isotope simulation using reanalysis atmospheric data, J. Geophys. Res.-Atmos., 113, D19108, doi:10.1029/2008JD010074, 2008.

Yoshimura, K., Kanamitsu, M., and Dettinger, M.: Regional downscaling for stable water isotopes: A case study of an atmospheric river event, J. Geophys. Res.-Atmos., 115, D18114, doi:10.1029/2010JD014032, 2010. 